\title{
Why it is Called Monosegmented Flow Analysis
}

\author{
Celio Pasquini
}

Instituto de Química, Universidade Estadual de Campinas, C.P. 6154,

\section{3-970 Campinas - SP, Brazil}

Sirs: A recently published paper $^{1}$ reviews a flow technique that was initially described in 1985 , based on the introduction of the sample between two air or inert gas bubbles in the flow analysis manifold ${ }^{2}$. This procedure generates a reproducible sample monosegment having restricted convection mixing with the carrier solution resulting in low dispersion of the sample during its transport to the detector, even with long residence times. Figure 1 compares flow patterns generated by three well known flow analysis systems. From the chemical point of view the monosegmented technique permits performing determinations under non-steady state conditions, ensured by the high timing reproducibility found in the monosegmented system due the presence of but two gas bubbles. This monosegmented system contrasts with the previous multisegmented systems (see Fig. 1B) originally described by Skeggs ${ }^{3}$. However, the main advantage of the monosegmented system is that the signal is obtained after allowing most of the reaction to take place, under the conditions of restricted dispersion of the sample (i.e. near the equilibrium state). From the physical point of view the steady state flow is more closely approximated by a monosegmented system than by the flow injection system.

The first paper introducing the new flow principle named it as Monosegmented Continuous Flow Analysis $(\mathrm{MCFA})^{2}$. This name remained in use until the recommendations of IUPAC on the classification and definition of

A

B

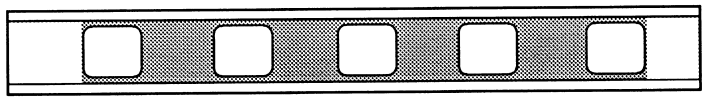

$\mathrm{C}$

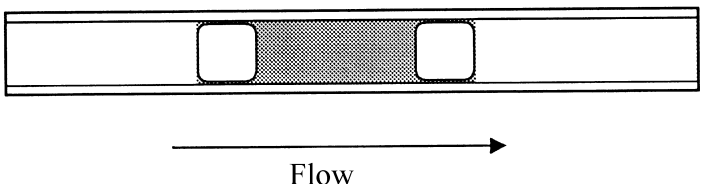

Figure 1. Sample profiles assumed in: A, Flow Injection systems; B, Multisegmented systems and C, Monosegmented systems. The grey areas represent the regions occupied by the sample. The distinct flow patterns impart unique characteristics to the different systems. The scale for the transporting tubing reflects the practical reported values ( 0.5 to $1.0 \mathrm{~mm}$ for FI and 1.5 to $2.5 \mathrm{~mm}$ for the segmented systems). analytical methods based on flowing media were published $^{4,5}$. Since then, many authors have recognized that the word "continuous" does not contribute significantly to the description of the flow process, and have accepted the name recommended by IUPAC: Monosegmented Flow Analysis (MSFA) $)^{4,5}$. A survey of the Institute for Scientific Information (ISI) data base reveals that, so far, 29 papers have employed the "monosegmented" word to describe this flow principle ${ }^{2,6-33}$ while only 3 works appearing in the ISI indexed periodicals have employed the term Segmental Flow Injection ${ }^{1,34,35}$ referring to the same flow approach. Unfortunately, the author of the review ${ }^{1}$ ignores the IUPAC recommendations ${ }^{4,5}$, preferring to use the name that he and his co-authors suggested five years after ${ }^{34}$ the first paper on the monosegmented technique was published $^{2}$. Note that in the paper in which the name SFIA was first coined ${ }^{34}$, no mention the of earlier papers ${ }^{2,6}$ was made.

In the review, the author suggests that "MSFA is not effective in emphasizing some essential features of the technique $^{1 "}$. He argues that, since the sample is injected, the word "injection" should be used in the name, as proposed by him. In fact, in most cases the sample is injected into the manifold by using a special injection device capable of generating the monosegment. However, the monosegment can also be produced by successively aspirating air and sample and flushing the monosegment with a carrier liquid in a flow system ${ }^{23,29,36}$ or by using a time based sampling system $^{17}$. No injection per se is employed in these cases while the characteristics of the monosegmented system are maintained. Thus the name need not/should not contain the term "injection", as was noted in the IUPAC recommendations ${ }^{4,5}$. On the other hand, it is possible to find at least one paper in the literature describing injection of the sample and subsequent multisegmentation ${ }^{37}$. The name Segmental Flow Injection Analysis does not distinguish between mono and multisegments, although they present completely different properties.

The review ${ }^{1}$ emphasizes early systems where the necessity of bubble removal was mandatory and resulted in significant dispersion, reducing the sensitivity or calling for larger sample volumes. An early paper was published aiming only at resolving this problem ${ }^{6}$. Actually, with the modern detection systems based on the microcomputer and digitized signals, the bubbles can pass through the detection 
cell, even when spectrophotometric detection is employed $^{19,20,21,27}$. Figure 2 shows a typical signal obtained using a computer based system that precludes bubble removal. Obviously, it looks more like a steady state signal than a flow injection signal because the concentration along the monosegment is essentially constant and the monosegment is nearly homogeneous ${ }^{21,27}$. This results in the signal based on a monosegment being independent of differences of refractive index among samples, overcoming problems due to the Schlieren effect ${ }^{27}$.

Not mentioned in the review ${ }^{1}$ is the unsurpassed advantage of the monosegmented approach: the ability of precise sample location which is possible because the sample is unambiguously present between two air bubbles as a single segment. This feature allows attaining a simple and complete management of the flow analyzer. Reagents can be selectively delivered only into the monosegment, where they are homogeneously distributed, allowing for a low consumption of expensive chemicals and for the use of the same manifold for a sequential determination of various analytes $^{21}$. Simple optical switches and conditioning electronic circuits capable of distinguishing between the refractive indexes of air and solution are used to produce electronic logical level transitions (TTL) to flag the controlling computer about the passage of the gas/liquid boundaries that define the monosegment ${ }^{38}$. In contrast with other flow systems, in a MSFA system it is always possible to know precisely where the sample is, allowing the appro-

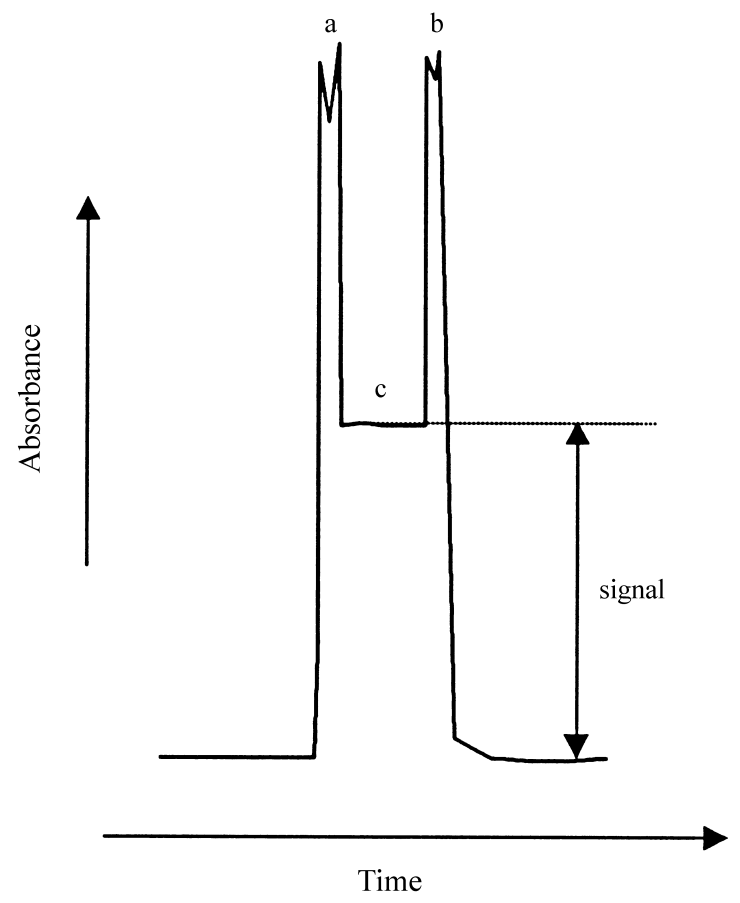

Figure 2. Typical signal obtained with a spectrophotometric detection in a monosegmented flow system. a and b: large absorbance change provided by the passage of the air bubbles through the flow cell; c: steady signalobtained during the passage of the monosegment through the flow cell. priate action to be implemented with the objective of conditioning, reaction or measurement. For example, the detection of the monosegement is made only when it is inside the flow cell ${ }^{20}$. The operation can be controlled by looking at the position of the first bubble immediately at the outlet of the flow cell.

Nobody can deny the enormous contribution of the Flow Injection concept ${ }^{39}$ to Analytical Sciences in general. The principle of dispersion controlled by convection/ diffusion is at the heart of this flow technique and it is achieved only by the non-segmented flow approach. On the other hand, the monosegmented approach uses a different principle and the use of a similar terminology would be confusing, as correctly interpreted by IUPAC $C^{3,4}$. In fact, the MSFA works in a distinct way, restricting the dispersion by compartmentalization. In doing so it provides many advantages as well as some disadvantages.

Thus, even without considering the recommendations of IUPAC ${ }^{4,5}$ it should be clear that Monosegmented Flow Analysis (MSFA) is the appropriate name for a flow approach which proposes the introduction of the sample in between two air bubbles, defining a monosegment, especially in view of the fact that this approach permits new features not achieved in previous flow approaches. The name MSFA communicates the main feature of the flow technique (the existence of the monosegment) and should remain the name for this rapidly growing flow analysis procedure.

The author is grateful to Dr. Carol H. Collins for helpful suggestions and manuscript revision.

\section{References}

1. Zhi, Z.L. Trends Anal. Chem. 1998, 17, 411.

2. Pasquini, C.; de Oliveira, W.A. Anal. Chem. 1985, 57, 2575.

3. Skegg Jr., L.T. J. Clin. Pathol. 1957, 28, 311.

4. Van der Linden, W.E. Pure Appl. Chem. 1994, 66, 2494.

5. Zagatto, E.A.G.; Oliveira, C.C.; Collins, C.H. Quim. Nova 1999, 22, 143.

6. Pasquini, C. Anal. Chem. 1986, 58, 2346.

7. de Andrade, J.C.; Loboschi, E.M. Analyst 1988, 113, 295.

8. de Andrade, J.C.; Ferreira, M.; Baccan, N.; Bataglia, O.C. Analyst 1988, 113, 289.

9. Reis, B.F.; Arruda, M.A.Z.; Zagatto, E.A.G.; Ferreira, J.R. Anal. Chim. Acta 1988, 206, 253.

10. de Andrade, J.C.; Eiras, S.P.; Bruns, R.E. Anal. Chim. Acta 1991, 255, 149.

11. de Faria, L.C.; Pasquini, C. J. Autom. Chem. 1992, 14, 213.

12. de Andrade, J.C.; Bruns, R.E.; Eiras, S.D. Analyst 1993, 118, 213. 
13. Nogueira, A.R.A.; Brienza, S.M.B.; Zagatto, E.A.G.; Lima, JLFC.; Araújo, A.N. Anal. Chim. Acta 1993, $176,121$.

14. dos Reis, B.F.; Zagatto, E.A.G.; Martelli, P.B.; Brienza, S.M.B. Analyst 1993, 118, 719.

15. Facchin, I.; Martins, J.W.; Zamora, P.G.P.; Pasquini, C. Anal. Chim. Acta 1994, 285, 287.

16. Facchin, I.; Pasquini, C. Anal. Chim. Acta 1995, 308, 231.

17. de Andrade, J.C.; Poppi, R.J.; Coscione, A.R. J. Autom. Chem. 1996, 18, 199.

18. Bellato, C.R.; Pasquini, C. Analyst 1996, 121, 1923.

19. Facchin, I.; Rohwedder, J.J.R.; Pasquini, C. J. Autom. Chem. 1997, 19, 33.

20. da Silva, M.C.H. and Pasquini, C., Anal Chim. Acta 1997, 349, 377.

21. Raimundo Jr., I.M.; Pasquini, C. Analyst 1997, 122, 1039.

22. Araújo, A.N.; Catita, J.A.M.; Lima, J.L.F.C.; Zagatto, E.A.G. Fresenius J. Anal. Chem. 1998, 360, 100.

23. Vieira, J.A.; Raimundo Jr., I.M.; Reis, B.F.; Zagatto, E.A.G.; Lima, J.L.F.C. Anal. Chim. Acta 1998, 366, 257.

24. da Silva, M.C.H.; Rohwedder, J.J.R.; Pasquini, C. Anal. Chim. Acta 1998, 366, 223.

25. Nielsen, S.; Hansen, E.H. Anal. Chim. Acta 1998, 366, 163.

26. Facchin, I.; Pasquini, C. Quim. Nova 1998, 21, 60.
27. Brito, V.O.; Raimundo Jr., I.M. Anal. Chim. Acta 1998, 371, 317.

28. Sotomayor, P.T.; Raimundo, I.M.; Neto, G.O.; de Oliveira, W.A. Sensor Actuat. B-Chem. 1998, 51, 382.

29. Ganzarolli, E.M.; Lehmkuhl, A.; de Queiroz, R.R.R.; Souza, I.G. Quim. Nova 1999, 22, 53.

30. Smiderle, M.; Reis, B.F.; Rocha, F.R.P. Anal. Chim. Acta 1999, 386, 129.

31. Honorato, R.S.; Silva, E.C.; de Araújo, M.C.U.; Veras, G.; Santos, S.R.B.; Lima, J.L.F.C.; Lapa, R.A.S. Lab. Robotics Automat. 1999, 11, 97.

32. Araújo, A.N.; Catita, J.A.M.; Lima, J.L.F.C. Farmaco 1999, 54, 51.

33. Martelli, P.B.; Reis, B.F.; Korn, M.; Lima, J.L.F.C. Anal. Chim. Acta 1999, 387, 165.

34. Tian, L.C.; Sun, X.P.; Xu, Y.Y.; Zhi, Z.L. Anal. Chim. Acta 1990, 303, 183.

35. Borzitsky, J.A.; Dvinin, A.V.; Petrukhin, O.M.; Urusov, Y.I. Anal. Chim. Acta, 1993, 274, 125.

36. Peterson, K.L.; Logan B.K.; Christian G.D.; Ruzicka, J. Anal. Chim. Acta, 1997, 337, 99.

37. Gardner, W.S.; Malczyk, J.M. Anal. Chem. 1983, 55, 1645.

38. Raimundo Jr., I.M.; Pasquini, C. Lab. Micro. 1994, 13, 55.

39. Ruzicka, J.; Hansen, E.H. Anal. Chim. Acta 1975, 78, 145.

Received: September 30, 1999

FAPESP helped in meeting the publication costs of this article 